\title{
Human triosephosphate isomerase: substitution of Arg for Gly at position 122 in a thermolabile electromorph variant, TPI-Manchester
}

\author{
B. A. Perry and H.W. Mohrenweiser \\ Biomedical Sciences Division, L-452, Lawrence Livermore National Laboratory, Livermore, CA 94550, USA
}

Received March 6, 1991 / Revised August 2, 1991

\begin{abstract}
Summary. Denaturing gradient gel electrophoreses of polymerase chain reaction amplified DNA products and subsequent direct sequencing identified a G-to-A transition causing a replacement of Gly 122 with Arg in an electrophoretic mobility variant of human triosephosphate isomerase, TPI-Manchester. This was the only TPI electromorph variant detected in screening of $>3,400$ humans in an Ann Arbor, Mich. population. This substitution is at the amino terminus or solvent interaction end of the fifth $\beta$ sheet of the $\alpha / \beta$ barrel structure. The TPI-Manchester variant is a thermolabile enzyme, but the stability of the variant enzyme is not sensitive to other denaturants. This amino acid substitution does not involve residues of the active site and does not detectably alter the kinetic properties of the enzyme. The data provide additional insight into the amino acid residues that are important for the maintenance of the structural characteristics of this very evolutionary constrained protein.
\end{abstract}

\section{Introduction}

Triose phosphate isomerase (TPI; EC 5.3.1.1), a homodimeric enzyme, is noted for its high catalytic efficiency and evolutionary conservation. The interconversion of dihydroxyacetone phosphate and glyceraldehyde phosphate is enhanced by a factor of $\sim 10^{10}$ in the presence of the enzyme (Albery and Knowles 1976; Nickbarg and Knowles 1988). The rate of catalysis is one of the highest known and the reaction rate is diffusion limited (Rose et al. 1990). The structural features of the enzyme are well documented, and crystallographic studies have been conducted on the enzyme from six organisms (Lolis et al. 1990). TPI is composed of an eight-stranded $\alpha / \beta$ barrel structure and is considered the prototype for this barrel folding pattern that has been identified in many other enzymes (Lolis et al. 1990). Genetically engineered var-

Offprint requests to: $\mathrm{H}$. Mohrenweiser iants of the enzyme have been used to study the reaction mechanism (Straus et al. 1985), subunit interactions (Casal et al. 1987), and the thermostability of the enzyme (Ahern et al. 1987).

Given the apparent evolutionary constraints on acceptable amino acid substitutions, it is not surprising that less than ten electrophoretic mobility variants have been identified during the screening of over 30,000 humans from several different populations by a series of investigators (Harris et al. 1974; Mohrenweiser et al. 1987; Neel et al. 1988). In contrast to the infrequent electromorph variation, some 20 unrelated cases of homozygosity for TPI deficiency are known (Tanaka and Zerez 1990). The frequency of individuals heterozygous for a null allele at this locus ranges from two variants/1000 individuals screened in Japanese (Neel et al. 1988), U.S. Caucasians (Mohrenweiser 1987), and Europeans (Eber et al. 1984) to four variants/100 individuals in American blacks (Mohrenweiser 1987; Mohrenweiser and Fielek 1982). It has been suggested that some combinations of these null alleles result in embryo lethality (Mohrenweiser and Fielek 1982); in the mouse, embryo lethality associated with homozygosity for null alleles is observed (Merkle and Pretsch 1989).

One of the electromorph variants identified during the screening of human populations, TPI Manchester, exhibits cathodal mobility relative to the normal human isozyme (Decker and Mohrenweiser 1981, 1985). Normal levels of enzyme activity are observed in erythrocytes of the heterozygous variant individuals (parent and child), and the variant isozyme has normal kinetic parameters (Asakawa and Mohrenweiser 1982). The TPIManchester variant exhibits increased thermolability relative to the normal isozyme but is not sensitive to inactivation by urea, guanidine, acid $\mathrm{pH}$, or basic $\mathrm{pH}$. We report the utilization of denaturating gradient gel electrophoresis (DGGE) of polymerase chain reaction (PCR) amplified fragments of the TPI gene and subsequent sequence analysis to identify a nucleotide substitution generating a glycine to arginine substitution in the variant enzyme. 


\section{Materials and methods}

\section{$D N A$ isolation}

Control DNA was isolated (Maniatis et al. 1982) from human placental tissue whereas variant DNA was isolated from a lymphoblastoid cell line, UM-121 (Decker and Mohrenweiser 1986). The TPI isozyme pattern in the UM-121 cell line is identical to the pattern previously observed in erythrocytes and lymphocytes from the proband.

\section{PCR amplification}

Primer pairs designated TPI-NA/NB, $-3 / 11$ and $-9 / 10$ were used for PCR amplification.

$\begin{array}{lll}\text { TPI-NA } & \text { 5'-GCGCGCGACACTGAC- } & (-39) \\ & \text { CTTCAGC-3' } & \\ \text { TPI-NB } & \text { 5'CCTCGGGAGAGGCTG- }^{\prime} \text { (186-anticoding) } \\ & \text { CTGCCAC-3' } & (1279) \\ \text { TPI-3 } & \text { 5'-TAGTCTCATCCCCTG- } & \\ & \text { TGGTACC-3' } \\ \text { TPI-11 } & \text { 5'-CCTCTGAGTCTCTGT- } & (1897-\text { anticoding) } \\ & \text { GGCCCT-3' } \\ \text { TPI-9 } & \text { 5'-CGCGCCCCGCGCCCC- } & (1916) \\ & \text { GTCCCGCCGCCCGCGGCC- } \\ & \text { GCCCGCCCGCCTGTCTCG- } \\ & \text { GTCCCCATGCTGATC-3' } \\ \text { TPI-10 } & \text { 5'-GCCGGCCACCGCCCC- } \\ & \text { GCGGCCGCCCGCCGCCCG- } & (2885-\text { anticoding) } \\ & \text { CGCCGCGCTGCTTAGTCC- } \\ & \text { CTGGCTTGGCA-3' }\end{array}$

The position of the $5^{\prime}$ nucleotide of each primer is indicated relative to the sequence of the chimpanzee gene (Craig et al 1991) as the complete sequence of the human gene is not available. The primers are located within intron regions. TPI primers 9 and $10 \mathrm{al}-$ lowed the integration of a GC-rich oligomer or "GC-clamp" (Sheffield et al. 1989) at both ends of the PCR product. The three PCR products include all seven TPI exons and with the exception of intron 1, most of the intron regions (Fig. 1a). Primer pair NA/NB allowed for the amplification of exon 1 plus contiguous flanking sequences whereas primers $3 / 11$ and $9 / 10$ amplified exons $2,3,4$ and exons $5,6,7$, respectively, plus associated intronic regions.

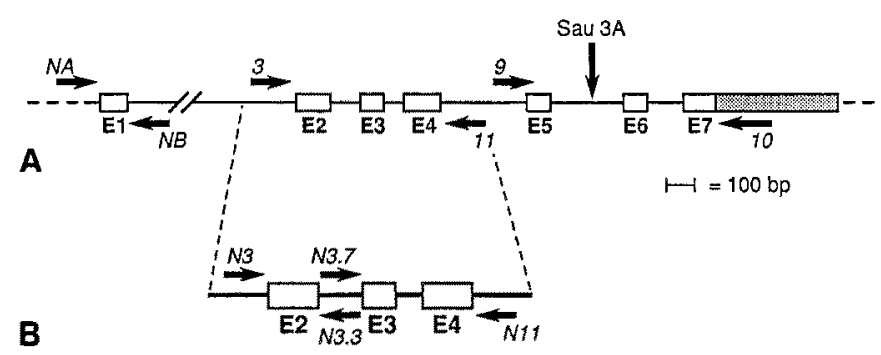

Fig. 1. A Schematic representation of primers for amplification of the human triosephosphate isomerase (TPI) gene. Arrows indicate position and orientation of primer pairs $\mathrm{NA} / \mathrm{NB}, 3 / 11$, and $9 / 10$, which were used to generate PCR products containing exons 1,24 , and $5-7$, respectively. Primers were located in regions flanking the various exons. Digestion with $\mathrm{SauA} 3$ was used to divide the primer $9 / 10$ product into two smaller fragments containing exons 5 and 6-7, respectively. B Scheme for utilization of nested sequencing primers to determine the position and the nature of putative base substitution in the PCR product that includes exons 2-4. Nested primers N3, N3.3, N3.7, and N11 were employed to facilitate bidirectional dideoxy sequencing of regions containing exons 2,3 , and 4
All PCR reactions were carried out as described by Sakai et al. (1988) with a DNA thermal cycler (Perkin Elmer Cetus, Norwalk, Conn.). Each $100 \mu \mathrm{l}$ reaction contained $\sim 2 \mu \mathrm{g}$ of genomic DNA, $200 \mathrm{ng}$ of each primer, $200 \mu M$ of each dNTP, $50 \mathrm{mM} \mathrm{KCl}, 10 \mathrm{mM}$ HEPES (pH 8.0), $1.5 \mathrm{mM} \mathrm{MgCl}, 0.02 \%$ gelatin (Sigma) $0.5 \%$ NP-40, and 2 units of Taq DNA polymerase (PE Cetus). Cycle parameters were as follows: $94^{\circ} \mathrm{C}, 2 \mathrm{~min}$; denaturation at $94^{\circ} \mathrm{C}$, $1 \mathrm{~min} ; 55^{\circ} \mathrm{C}, 30 \mathrm{~s}$; annealing at $55^{\circ} \mathrm{C}, 20 \mathrm{~s} ; 72^{\circ} \mathrm{C}, 2 \mathrm{~min}$; elongation at $72^{\circ} \mathrm{C}, 1$ min for 30 cycles, followed by an incubation period of $10 \mathrm{~min}$ at $72^{\circ} \mathrm{C}$ to ensure full length amplification products. After $200 \mu \mathrm{l}$ of chloroform was added and the lower, mineral oil-chloroform phase was discarded, $20 \mu \mathrm{l}$ of loading buffer - TE $(10 \mathrm{mM}$ Tris- $\mathrm{Cl}, \mathrm{pH} 7.9$ and $1 \mathrm{mM}$ EDTA), $15 \%$ Ficoll type $400,0.2 \%$ bromphenol blue, and $0.2 \%$ xylene cyanol - was added to the remaining aqueous reaction volume before loading onto the denaturing gels.

In the case of PCR product from primers 9 and 10 , the amplified product was digested with the restriction enzyme Sau $3 \mathrm{~A}$ to generate fragments of 503 bp (containing exon 5) and 517 bp (containing exons 6 and 7), each with a GC-clamp at one end, before addition of the loading buffer. As suggested by Sheffield et al. (1989), this strategy facilitated the DGGE screening and with the utilization of different restriction enzymes should allow for the more refined region localization of the nucleotide sequence variation.

\section{Denaturing gradient gel electrophoresis}

Denaturing gradient gel electrophoresis (DGGE) was performed as described by Myers et al. $(1985,1988)$. All PCR products were initially screened on 1.5 -mm-thick denaturing acrylamide gels containing a broad linear gradient of $30 \%-70 \%$ denaturant $(100 \%=$ $7 \mathrm{M}$ urea and $40 \%$ formamide), $10 \%$ acrylamide ( $1.08 \%$ bis) and $1 \times$ TAE $(0.04 M$ Tris-acetate and $0.001 M$ EDTA $)$ in order to determine the optimal gradient range for resolution of each amplified fragment. Gels were immersed in a $60^{\circ} \mathrm{C}$ circulating bath of $1 \times$ $\mathrm{TAE}$ and electrophoresis was for $12-16 \mathrm{~h}$ at $25 \mathrm{~mA}$. Subsequent analysis employed the following gradients: exon 1 fragment, $40 \%-$ $70 \%$; exons $2-4$ fragment, $40 \%-60 \%$; exons $5-7$ fragments, $40 \%-$ $60 \%$. Following electrophoresis, the gels were stained with ethidium bromide and the migration profiles visualized with ultraviolet illumination.

\section{DNA sequencing}

To provide templates for sequencing, the band corresponding to each allelic form (normal and variant) of a particular PCR product was directly excised from the denaturing gradient gel. The acrylamide gel slice was soaked for $20 \mathrm{~min}$ in TE, then placed into a microfuge tube and ground to a fine consistency. After $0.2 \mathrm{ml}$ of $0.1 \times$ TE was added and the contents vigorously vortexed for 1-3 min, the contents were centrifuged to consolidate the acrylamide debris.

To generate double-stranded DNA for sequencing, a small

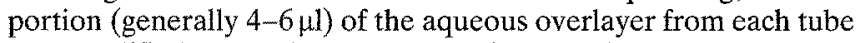
was amplified as previously described, using the same primers as originally employed to generate each product. After amplification, the DNA was purified using a Bioclean kit (United States Biochemical Corp. Cleveland, Ohio).

Each allelic form of the PCR product containing exons 2-4 from TPI-Manchester was sequenced bidirectionally by the dideoxy method (Sanger and Coulson 1975) using a Sequenase ${ }^{1}$ kit and Sequenase version 2.0 T7 DNA polymerase (USB). The sequencing strategy employed two sets of nested primers:

N3: $\quad 5^{\prime}$-ATCTTGCCCTCAGAGGTG-3' (1295),

N3.3: 5'-ACACACCCCTCTCCACCTCG-3' (1465),

N3.7: $5^{\prime}$-ACCTTGGCTTCATCTCTTCC-3' (1526) and

N11: 5'-CAAGGTCCCTTTCTCAGAG-3' (1866).

N3 and N3.3 allowed for the bidirectional sequencing of TPI exon 2 from noncoding sequences flanking the upstream and down- 
stream ends of the exon respectively. N3.7 and N11 allowed for sequencing of the fragment containing TPI exons 3 and 4 together, in a similar fashion (Fig. 1b). Approximately $50 \mathrm{ng}$ of PCR-amplified TPI $3 / 11$ product was combined with 20 pmol of one of the four nested TPI primers, $2 \mu$ l of $5 \times$ reaction buffer and $0.5 \% \mathrm{NP}$ 40 in a total reaction volume of $10 \mu \mathrm{l}$. The contents were heated at $98^{\circ} \mathrm{C}$ for $5 \mathrm{~min}$ and immediately transferred to a dry ice-ethanol bath. All subsequent reactions were performed as suggested by the manufacturer with $\alpha^{35} \mathrm{~S}-\mathrm{dATP}(1000 \mathrm{Cl} / \mathrm{mmol})$; the products were fractionated on an $8 \%$ polyacrylamide sequencing gel.

\section{Results}

\section{Denaturing gradient gel electrophoresis}

The results of the DGGE analysis of the three TPI PCR products from both control and TPI-Manchester genomic DNA samples are shown in Fig. 2. As seen in Fig. $2 \mathrm{~A}$, only a single band, with identical mobility in both normal and variant DNA, was observed for the fragment that included exon 1. In Fig. 2B, two bands are observed in both samples when the Sau3A-digested PCR amplified fragment that includes exons 5-7 is examined. The upper band includes exon 6 and 7 while the lower band includes exon 5. Each of the Sau3A fragments migrated as single bands under their respective DGGE conditions. The exons 5-7 fragment was also amplified using primers without GC-tails, and again identical mobility fragments were observed in both normal and variant samples (data not shown). Primers spanning the Sau3A site were generated in order to be able to amplify the exon 5 and exons 6 plus 7 fragments independently. Only a single band was observed in each sample from both variant and normal individuals following DGGE of these fragments.

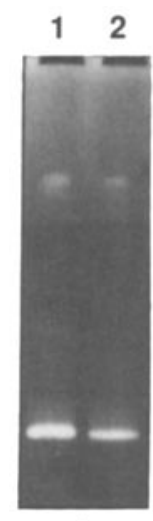

A

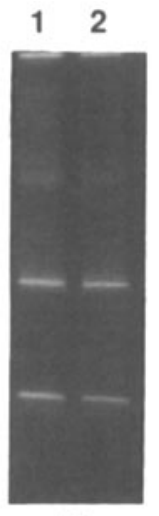

B

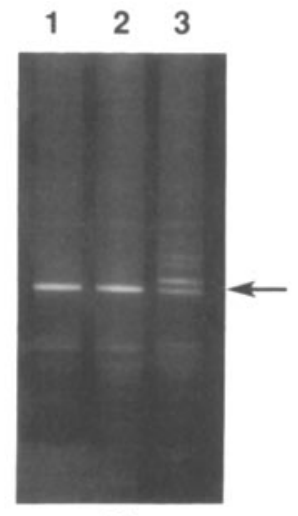

C
Fig. 2A-C. Denaturing gradient gel depicting electrophoretic profiles of the PCR fragments from control and TPI-Manchester variant genomic DNA. A DGGE profile of the amplification product from primers NA/NB from control (lane 1) and variant (lane 2) individuals following electrophoresis through a $40 \%-70 \%$ denaturant gradient; B profile of the Sau3A-digested primers $9 / 10$ product from control (lane 1) and variant (lane 2) individuals following electrophoresis through a $40 \%-60 \%$ denaturant gradient. The upper and lower bands contain exons $6-7$ and 5 , respectively; $\mathbf{C}$ profile of the primers $3 / 11$ product from control (lanes 1 and 2 ) and variant (lane 3 ) individuals following electrophoresis through a $40 \%-60 \%$ denaturant gradient. The arrow indicates the normal (lower band) and variant (upper band) homoduplexes
Thus, no evidence for a nucleotide sequence difference in the exon 5-7 region between the normal and variant allele was detected.

The segregation of the 584-bp product, which includes exon $2-4$, into two bands suggested the existence of two allelic forms of this particular PCR product within the genome of the TPI-Manchester individual (Fig. 2C). Since the lower band comigrates with the only band derived from several non-variant samples, it was presumed to represent the normal allelic form of the exon 2-4 fragment. The upper band should correspond to the fragment from the variant allele. The two additional, less stable bands of lower staining intensity are presumably heteroduplexes formed during the annealing step of the last PCR amplification cycle. As the variant allele gives rise to a protein with normal activity but altered mobility (Decker and Mohrenweiser 1982), the substitution, if responsible for the shift in the electrophoretic mobility of the enzyme, presumably resides in exon 2,3 , or 4 rather than in an intron.

DNA from 16 additional, unrelated individuals (32 alleles) was studied for evidence of sequence variation detectable with the PCR/DGGE assay. The PCR primers utilized to generate the DNA fragments in this screen were the six pairs described above, plus two pairs of primers that generated exons 2 plus 3 and 4 as unique fragments. Fragments that included most of the TPI gene with the exception of intron 1 and totaling 1812 nucleotides in length were generated from each sample. No evidence of a double-banded pattern following DGGE of any of the fragments was detected in any individual. Thus, within the limits of detectability by the DGGE assay, no nucleotide substitutions were identified in the $\sim 55 \mathrm{~kb}$ of DNA generated in samples from this population, indicating that any variant alleles that might be detected by DGGE would exist with a frequency of less than $3 \%-$ $5 \%$.

\section{Sequence analysis}

Sequence analysis of the normal and variant allelic fragments of the 584-bp PCR product from exons 2-4 derived

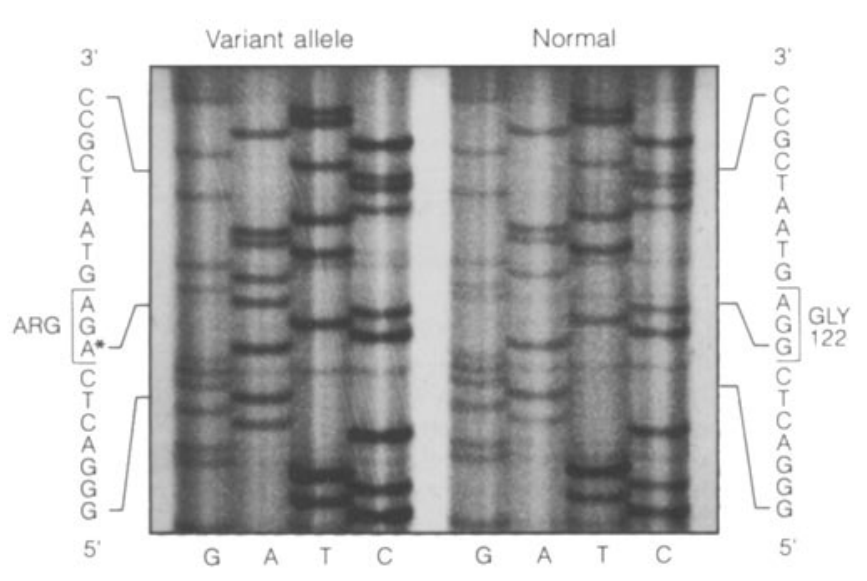

Fig. 3. Sequence data from TPI exon 4. Asterisk indicates position of the G-to-A base substitution in the variant allele resulting in the replacement of a glycine with an arginine 
from TPI-Manchester revealed a G-to-A transition in exon 4 at nucleotide 1752 (Fig. 3) using the numbering system of the chimpanzee gene (Craig et al. 1991) or nucleotide 366 in the human cDNA sequence (Marquat et al. 1985). This nucleotide substitution changes the amino acid of codon 122 from glycine to arginine. All other sequence data derived from the normal and variant alleles of this PCR product were consistent with that previously published for the human (Marquat et al. 1985) and primate (Craig et al. 1991; Old and Mohrenweiser 1988) genes. This sequence variation in the variant allele was observed in samples produced from several independent amplifications of the genomic DNA, thereby reducing the probability that the variation is associated with errors induced by the polymerase enzyme during amplification.

\section{Discussion}

The sequence of the TPI enzyme from 13 organisms including bacteria, plants, and animals is known (see Lolis et al. 1990). The intron-exon boundary positions have been extensively retained in widely divergent species (Marchionni and Gilbert 1986). The overall amino acid homology is $\sim 50 \%$ for such distantly related organisms as Escherichia coli (Straus and Gilbert 1985) and man (Brown et al. 1985), with 22\% of the residues being identical in the enzyme from all species. The enzyme from human and rhesus (Macaca mulatta) differ by only 2 of 248 amino acid residues, and the nucleotide sequence identity in the exons is $97 \%$ (Old and Mohrenweiser 1988; Old et al. 1989). Rhesus and chimpanzee differ by $<2 \%$ in the exon segments, and the sequence divergence in the intron segments is $<10 \%$. The 750 nucleotide coding sequences in human and chimpanzee differ at only five positions (Craig et al. 1991). The sequence identity for $>500$ nucleotides at both the $3^{\prime}$ and $5^{\prime}$ ends of the TPI genes in human and chimpanzee is over $98 \%$, and similar identity for these regions exists between chimpanzee and rhesus. Thus, the evolutionary constraints on sequence divergence observed at the protein level also extend to the nucleotide level and include regions in addition to the exons. The absence of detectable allelic variation among the individuals in this sampling of the human population is consistent with the limited evolutionary divergence. It should be noted that nucleotide substitutions that are not resolved by DGGE or that exist in intron regions not screened could still be present in the human population.

The enzyme from all organisms studied has similar kinetic properties, and critical amino acid residues involved in catalysis are invariant in distantly related organisms, including $E$. coli and human (see Lolis et al. 1990). Crystallographic analyses of the enzyme from yeast and chicken indicate similar conservation in structural conformation (Lolis et al. 1990), although significant differences in thermostability are noted in the enzymes from various organisms (Naidu et al. 1984).

The nucleotide substitution identified in the variant allele was in codon 122 , which is located at the amino terminal end of the fifth $\beta$-strand. This segment corresponds to amino acid residues $122-127$ of the yeast enzyme (Lolis et al. 1990). (The numbering of the amino acid residues is the same in the yeast and human enzyme). The eight $\beta$-strands of the enzyme are composed of predominantly hydrophobic residues except for the amino terminal residues where the barrel is exposed to solvent. The opposite or carboxyl end of the barrel is most directly involved in the active site. Therefore, variation in residue 122 would not be expected to alter the interaction of the substrate with the active site, and this is consistent with the failure to detect any differences in kinetic parameters between the normal and variant homodimers. Residue 122 is glycine in the enzyme from 7 of 13 organisms, ranging from Saccharomyces cerevisiae (Alber and Kawasaki 1982) to human, for which the enzyme has been characterized. The corresponding residue in the other species includes lysine and glutamine residues in the enzymes from maize (Marchionni and Gilbert 1986) and Aspergillus nidulans (McKnight et al. 1986), respectively, thus the existence of a positively charged residue at this position is not incompatible with normal enzymatic function.

TPI-Manchester is a thermolabile electromorph variant with a Gly-to-Arg substitution at residue 122. Other amino acid substitutions associated with thermolability of this enzyme have been identified. Daar et al. (1986) found than an unstable variant associated with TPI deficiency was due to a Glu-to-Asp substitution at residue 104. Ahern et al. (1987) demonstrated that substitution of Asp for Asn at residue 78 of the yeast enzyme increased the heat lability while replacement of the Asn residues 14 and 78 (both of which are at the subunit interface) with Thr and Ile, respectively, nearly doubled the thermostability of the enzyme. The enzyme from rhesus is also very thermolabile compared to the human isozyme, although the proteins differ by only two amino acid residues, Asn/Ser at residue 20 and Glu/Asp at residue 198 (Old and Mohrenweiser 1988). None of these residues are in the $\beta$-strands of the barrel structure.

Without detailed structural information derived from crystallographic analysis of the variant isozyme, it is not possible to define explicitly the effect that the replacement of a glycine residue with an arginine may have on the tertiary structure. However, the incorporation of a considerably bulkier, charged side chain at this position would have the potential for disrupting the compactness of folding, possibly resulting in an alteration of the tertiary structure, a phenomenon that would be consistent with the observed increase in thermolability.

Acknowledgements. This work was performed under the auspices of the U.S. Department of Energy, Office of Health and Environmental Research by the Lawrence Livermore National Laboratory under contract number W-7405-ENG-48.

\section{References}

Ahern TJ, Casal JI, Petsko GA, Klibanov AM (1987) Control of oligomeric enzyme thermostability by protein engineering. Proc Natl Acad Sci USA 84:675-679 
Alber T, Kawasaki G (1982) Nucleotide sequence of the triose phosphate isomerase gene from Saccharomyces cerevisiae. J Mol Appl Genet 1:419-433

Albery WJ, Knowles JR (1976) Evolution of enzyme function and the development of catalytic efficiency. Biochemistry $15: 5631$ 5640

Asakawa J, Mohrenweiser HW (1982) Characterization of two new electrophoretic variants of human triosephosphate isomerase: stability, kinetic, and immunological properties. Biochem Genet 20:59-76

Brown JR, Daar IO, Krug JR, Maquat LE (1985) Characterization of the functional gene and several processed pseudogenes in the human triosephosphate isomerase gene family. Mol Cell Biol 5:1694-1706

Casal JI, Ahern TJ, Davenport RC, Petsko GA, Kilbanov AM (1987) Subunit interface of triosephosphate isomerase: site-directed mutagenesis and characterization of the altered enzyme. Biochemistry 26:1258-1264

Craig LC, Pirtle IL, Gracy RW, Pirtle RM (1991) Characterization of the transcription unit and two processed pseudogenes of chimpanzee triosephosphate isomerase. Gene 99:217-231

Daar IO, Arrymiuk PJ, Phillips DC, Maquat LE (1986) Human triose-phosphate isomerase deficiency: a single amino acid substitution results in a thermolabile enzyme. Proc Natl Acad Sci USA 83:7903-7907

Decker RS, Mohrenweiser HW (1981) Origin of the triosephosphate isozymes in humans: genetic evidence for the expression of a single structural locus. Am J Hum Genet 33:683-691

Decker RS, Mohrenweiser HW (1985) Cell proliferation-associated expression of a recently evolved isozyme of triosephosphate isomerase. Biochem Genet 23:267-280

Decker RS, Mohrenweiser HW (1986) Hominoid triosephosphate isomerase: characterization of the major cell proliferation specific isozyme. Mol Cell Biochem 71:31-44

Eber SW, Dunnwald M, Heinemann G, Hofstatter T, Weinmann HM, Belohradsky BH (1984) Prevalence of partial deficiency of red cell triosephosphate isomerase in Germany: a study of 3000 people. Hum Genet 67:336-339

Harris H, Hopkinson DA, Robson EB (1974) The incidence of rare alleles determining electrophoretic variants: data on 43 enzyme loci in man. Ann Hum Genet 37:237-253

Lolis E, Alber T, Davenport RC, Rose D, Hartman FC, Petsko GA (1990) Structure of yeast triosephosphate isomerase at 1.9$A^{\circ}$ resolution. Biochemistry $29: 6609-6618$

Maniatis T, Fritsch EF, Sambrook J (1982) Molecular cloning: a laboratory manual. Cold Spring Harbor Laboratory, Cold Spring Harbor, NY

Maquat LE, Chilcote R, Ryan PM (1985) Human triosephosphate isomerase cDNA and protein structure. $J$ Biol Chem 260: 3748-3753

Marchionni M, Gilbert W (1986) The triosephosphate isomerase gene from maize: introns antedate the plant-animal divergence. Cell 46:133-141

McKnight GL, O'Hara PJ, Parker ML (1986) Nucleotide sequence of the triosephosphate isomerase gene from Aspergillus nidulans: implications for a differential loss of introns. Cell 46:143147

Merkle S, Pretsch W (1989) Characterization of triosephosphate isomerase mutants with reduced enzyme activity in Mus musculus. Genetics 123:837-844
Mohrenweiser HW (1987) Functional hemizygosity in the human genome: direct estimate from twelve erythrocyte enzyme loci. Hum Genet 77:241-245

Mohrenweiser HW, Fielek S (1982) Elevated frequency of carriers for triosephosphate isomerase deficiency in newborn infants. Pediatr Res 19:960-963

Mohrenweiser HW, Wurzinger KH, Neel JV (1987) Frequency and distribution of rare electrophoretic mobility variants in a population of human newborns in Ann Arbor, Michigan. Ann Hum Genet 51:303-316

Myers RM, Lumelsky N, Lerman LS, Maniatis T (1985) Detection of single base substitutions in total genomic DNA. Nature 313: 495-498

Myers RM, Sheffield VL, Cox DR (1988) Detection of single base changes in DNA: ribonuclease cleavage and denaturating gel electrophoresis. In: Davies K (ed) Genomic analysis: a practical approach. IRL Press, London pp 95-139

Naidu JM, Turner 'TR, Mohrenweiser HW (1984) Thermostability characteristics of glucosephosphate isomerase and triosephosphate isomerase in erythrocytes from several species. Comp Biochem Physiol 79B:211-217

Neel JV, Satoh C, Goriki K, Asakawa JI, Fujita M, Takahashi N, Kageoka T, Hazama R (1988) Search for mutation altered protein charge and/or function in children of atomic bomb survivors: final report. Am J Hum Genet 42:663-676

Nickbarg EB, Knowles JR (1988) Triosephosphate isomerase: energetics of the reaction catalyzed by the yeast enzyme expressed in Escherichia coli. Biochemistry 27:5939-5947

Old SE, Mohrenweiser HW (1988) Nucleotide sequence of the triosephosphate isomerase gene from Macaca mulatta. Nucleic Acids Res 16:9055

Old SE, Landa LE, Mohrenweiser HW (1989) Hominoid triosephosphate isomerase: regulation of expression of the proliferation specific isozyme. Mol Cell Biochem 89:73-85

Rose IA, Fung WJ, Warms JVB (1990) Proton diffusion in the active site of triosephosphate isomerase. Biochemistry $29: 4312-$ 4317

Sakai RK, Gelfand DH, Stoffel S, Scharf SJ, Higuchi R, Horn GT (1988) Primer-directed enzymatic amplification of DNA with a thermostabile DNA polymerase. Science 239:487-491

Sanger F, Coulson AR (1975) A rapid method for determining sequences in DNA by primed synthesis with DNA polymerase. J Mol Biol $94: 441-448$

Sheffield VC, Cox DR, Lerman L, Myers RM (1989) Attachment of a 40-base-pair $\mathrm{G}+\mathrm{C}$-rich sequence (GC-clamp) to genomic DNA fragments by the polymerase chain reaction results in improved detection of single-base changes. Proc Natl Acad Sci USA $86: 232-236$

Straus D, Gilbert W (1985) Chicken triosephosphate isomerase complements an Escherichia coli deficiency. Proc Natl Acad Sci USA 82: 2014-2018

Straus D, Raines R, Kawashima E, Knowles JR, Gilbert W (1985) Active site of triosephosphate isomerase: in vitro mutagenesis and characterization of an altered enzyme. Proe Natl Acad Sci USA $82: 2272-2276$

Tanaka K, Zerez CR (1990) Red cell enzymopathies of the glycolytic pathway. Semin Hematol 27:165-185 